\title{
FSHR Single Nucleotide Polymorphism Frequencies in Proven Fathers and Infertile Men in Southeast Turkey
}

\author{
Mahmut Balkan, ${ }^{1}$ Abdullah Gedik, ${ }^{2}$ Hasan Akkoc, ${ }^{3}$ Ozlem Izci Ay, ${ }^{4}$ M. Emin Erdal, ${ }^{4}$ \\ Hilmi Isi, ${ }^{1}$ and Turgay Budak ${ }^{1}$
}

${ }^{1}$ Department of Medical Biology and Genetics, Dicle University Medical Faculty, 21280 Diyarbakır, Turkey

${ }^{2}$ Department of Urology, Dicle University Medical Faculty, 21280 Diyarbakır, Turkey

${ }^{3}$ Department of Pharmacology, Dicle University Medical Faculty, 21280 Diyarbakır, Turkey

${ }^{4}$ Department of Medical Biology and Genetics, Mersin University Medical Faculty, 33169 Mersin, Turkey

Correspondence should be addressed to Mahmut Balkan, balkanmah@gmail.com

Received 23 December 2009; Revised 1 April 2010; Accepted 14 April 2010

Academic Editor: M. Ilyas Kamboh

Copyright (C 2010 Mahmut Balkan et al. This is an open access article distributed under the Creative Commons Attribution License, which permits unrestricted use, distribution, and reproduction in any medium, provided the original work is properly cited.

\begin{abstract}
The influence of FSH receptor (FSHR) variants on male infertility is not completely understood. The present investigation is the first screening study for SNP at nucleotide position -29 in the core promoter region and codon 680 in exon 10 of the FSHR and the effect of the serum levels of FSH on male infertility in Southeast Turkey. The SNPs in codon 680 and at position -29 of the FSHR gene were analyzed by PCR-RFLP technique in 240 men with proven fathers, and 270 infertile men (150 nonobstructive azoospermic and 120 severe oligozoospermic). The separate analysis for SNP at nucleotide position -29 did not show any difference in genotypic frequencies and serum FSH levels. The genotype distribution of SNP at position 680 was different but does not influence serum FSH levels. Together the two SNPs form four discrete haplotypes (A-Thr-Asn, G-Thr-Asn, A-Ala-Ser, and G-Ala-Ser) occurring in 10 combinations. A statistically significant difference in the allelic distribution of G-Asn/G-Ser and G-Ser/G-Ser genotype between proven fathers and infertile men but there were not any statistically significant difference in the overall frequency of the four FSHR haplotypes. We conclude that the FSHR haplotype does not associate with different serum FSH levels but it is differently distributed in proven fathers and infertile men.
\end{abstract}

\section{Introduction}

The interaction between follicle-stimulating hormone (FSH) and the FSH receptor (FSHR) is essential for normal oogenesis and spermatogenesis [1-15]. In the male, FSH is fundamental for Sertoli cell function and the induction and maintenance of qualitatively and quantitatively normal spermatogenesis by a specific receptor (FSHR) that is a member of the $G$ protein-coupled receptor family $[8,11]$. The FSHR gene spans a region of $54 \mathrm{~kb}$ on chromosome 2 p21 and consists of 10 exons and 9 introns $[3,8,11]$. The extracellular domain is encoded by exons 1 to 9; whereas exon 10 encodes the C-terminal part of the extracellular domain, the complete transmembrane, and the intracellular domain $[5,8,11]$. The activity of this gene is driven by a core promoter spanning $225 \mathrm{bp}$, which represents a TATAless promoter with no evident regulatory elements beside an
E-box $[8,9]$ and a more recently identified initiator element (Inr) [16].

Mutation screening of the FSHR gene revealed various single nucleotide polymorphisms (SNPs) both in the core promoter and in the coding region $[1,8,9,11,12]$. A common SNP that occurs in the core promoter at nucleotide position $-29(-29 \mathrm{G}>\mathrm{A})$ results in a G/A exchange in a potential GGAA binding domain for an E-26 transcription factor, which is altered $[3,11]$. The other most common SNP in the coding region occurs at nucleotide 2039 in exon 10, in which $\mathrm{A} / \mathrm{G}$ transitions cause amino acid exchange from asparagine to serine at codon 680 (N680S) $[7,8,11,12,14]$.

Investigations on the distribution of these SNPs produced varying results. In the normal and infertile men and women, some studies revealed that there is no difference in the distribution of SNP and they have no effect on serum FSH levels $[2,7,11,13,17,18]$; whereas other investigations 
found significant differences between patients and controls $[6,8,15,19,20]$, suggesting that ethnic differences could be involved.

This is the first study to determine the polymorphism of the FSHR core promoter at position -29 , alone and in combination with the SNP at codon 680 in exon 10, and to evaluate the possible role of these two FSHR SNPs on serum levels of FSH in Southeast Turkey.

\section{Materials and Methods}

2.1. Design. The study population consists of 240 proven fathers (sperm count $>20 \times 10^{6} / \mathrm{mL}$ and serum FSH levels <7 IU/L), and 270 infertile men (150 nonobstructive azoospermic and 120 severe oligozoospermic in which sperm count $<10 \times 10^{6} / \mathrm{mL}$ ) referred to Human Genetic Department of Dicle University Hospital. There were not seen karyotype abnormalities and Y chromosome long arm microdeletions in the study population. Since "infertile" men are a quite heterogeneous population and spermatogenesis can vary qualitatively and quantitatively in individual subjects, to increase the stringency of the study we selected only men with nonobstructive azoospermia and oligozoospermia compared them to proven fathers with normal spermatogenesis. This study was approved by the Hospital Ethics Committee (B.30.2.DİC.0.01.00.00/80), and written informed consent was obtained from all participants.

Genomic DNA was extracted from peripheral blood leucocytes by standard procedures [21, 22] before being analyzed by multiplex PCR. The SNPs at positions -29 of promoter [11] and at nucleotide 2039 (codon 680) of exon 10 [23] were analyzed using the polymerase chain reactionrestriction fragment length polymorphism (PCR-RFLP) technique with the primers which were designed based on the published sequence of the human FSHR gene. For position -29 (rs1394205) we used forward primer: 5'-TGG TGA ACA GCA AGG AGA CTT-3', reverse primer: 5' -TTG GCA GAG AAA AAC CCT GT-3', whereas for nucleotide 2039 genotyping (codon 680) (rs6166), forward primer: $5^{\prime}$-CCC AAA TTT ATA GGA CAG-3', reverse primer: 5'-GAG GGA CAA GTA TGT AAG TG-3. The PCR products were then digested with the restriction enzymes (MboII for -29 and BsrI for SNP Ser680Asn), according to the manufacturer's protocol. The PCR fragment following 2.5\% agarose gel electrophoresis shows three different patterns for -29 . The uncleaved fragment, homozygous for A, has a size of 404 bp; whereas the cleaved fragment, homozygous for $\mathrm{G}$, gives rise to 289 and 115 bp fragments. The Asn 680 allele gives an undigested fragment of $520 \mathrm{bp}$; whereas the Ser 680 allele gives two fragments of 413 and $107 \mathrm{bp}$. For heterozygous (Asn/Ser), agarose gel electrophoresis allows visualization of three bands $520 \mathrm{bp}, 413 \mathrm{bp}$, and $107 \mathrm{bp}$.

Semen analysis was performed according to the World Health Organization [24]. Serum concentrations of FSH were measured by electrochemiluminescence immunoassays (ECLIAs), using Roche Elecsys 1010 (Roche Diagnostics, Mannheim, Germany) according to the manufacturer's instructions.
2.2. Data Analysis. Statistical analysis was performed by applying a commercially available software package (SPSS 15.0 for Windows, SPSS, Chicago, Illinois, USA). Data were analyzed for normal distribution. Data are presented as mean \pm SEM. $\chi^{2}$ and one-way analysis of variance (ANOVA) tests were used for the analysis of the data. Statistical significance was set at $P \leq .05$.

\section{Results}

The separate analysis for SNP at nucleotide position -29 did not show any difference in genotypic frequencies between proven fathers and infertile patients $\left(\chi^{2}=1.182, P>.05\right)$ (Table 1). Similarly, SNP at nucleotide position -29 was not associated with different FSH concentrations in each group $(P>.05$, ANOVA) (Table 1$)$.

When the SNP at amino acid positions 680 was separately analyzed, a statistically significant difference was found in the genotype frequency between three groups $\left(\chi^{2}=22.87\right.$, $P<.001)$. Further testing by two-by-two statistics revealed significant difference for genotype Asn-Ser between proven fathers and nonobstructive azoospermic groups $\left(\chi^{2}=5.26\right.$, $P<.05)$, for genotype Ser-Ser between proven fathers and nonobstructive azoospermic groups $\left(\chi^{2}=6.67, P<.05\right)$, for genotype Asn-Ser between proven fathers and severe oligozoospermic groups $\left(\chi^{2}=5.18, P<.05\right)$, for genotype Asn-Ser between nonobstructive azoospermic and severe oligozoospermic $\left(\chi^{2}=15.36, P<.001\right)$, and for genotype Ser-Ser between nonobstructive azoospermic and severe oligozoospermic groups $\left(\chi^{2}=11.86, P<.05\right)$. To assess whether the polymorphism at 680 influences FSH levels, we compared FSH concentrations among genotypes. The FSH concentrations were not different between the FSHR genotypes for each group of patients and proven fathers $(P>.05$, ANOVA $)$.

When we analyzed the haplotypes determined by the two SNPs at position -29 and codon 680, our results show that four possible haplotypes result from all the two SNPs of the FSHR gene: A-Asn, G-Asn, A-Ser, and GSer. These haplotypes account is combined into the 10 major combinations shown in Table 2, in which nine groups are presented since the two possible allelic combinations of group 5 (double heterozygous) cannot be distinguished and are considered together. Further testing by Chi-square revealed the significant difference for G-Asn/G-Ser and GSer/G-Ser genotype in men with proven fathers and infertile (nonobstructive azoospermic and severe oligozoospermic). We then calculated the overall frequency of the four FSHR haplotypes in proven fathers and infertile men. As shown in Table 3, no statistically significant difference between the groups was found ( $P>.05$ by $\chi^{2}$ test). To assess whether the haplotypes influences FSH levels, we compared FSH concentrations among genotypes. There were no significant differences in the FSH levels among the FSHR genotypes in both the two groups of infertile and proven fathers $(P>.05$, ANOVA) (Table 2).

Test for deviation from Hardy-Weinberg proportions has been performed, and the deviation from the HardyWeinberg equilibrium (excess of homozygosity) takes place 
TABLE 1: Genotypic frequencies and serum FSH concentrations (mean \pm SD) in proven fathers and the two groups of infertile patients.

\begin{tabular}{|c|c|c|c|c|c|c|}
\hline \multirow[t]{2}{*}{ Allele combination } & \multicolumn{2}{|c|}{$\begin{array}{l}\text { Proven fathers } \\
\quad(n=240)\end{array}$} & \multicolumn{2}{|c|}{$\begin{array}{l}\text { Nonobstructive azoospermic } \\
\qquad(n=150)\end{array}$} & \multicolumn{2}{|c|}{$\begin{array}{l}\text { Severe oligozoospermic } \\
\qquad(n=120)\end{array}$} \\
\hline & $\begin{array}{l}\text { Genotypic frequency } \\
n(\%)\end{array}$ & FSH (IU/I) & $\begin{array}{l}\text { Genotypic } \\
\text { frequency } \\
n(\%)\end{array}$ & FSH (IU/I) & $\begin{array}{l}\text { Genotypic } \\
\text { frequency } \\
n(\%)\end{array}$ & FSH (IU/I) \\
\hline \multicolumn{7}{|l|}{ At position -29} \\
\hline AA & $13(5.4)$ & $3.4 \pm 0.4$ & $8(5.3)$ & $25.5 \pm 2.8$ & $6(5)$ & $11.9 \pm 4,8$ \\
\hline AG & $49(20.4)$ & $3.4 \pm 0.3$ & $26(17.3)$ & $23.6 \pm 1.4$ & $27(22.5)$ & $13.9 \pm 6.7$ \\
\hline GG & $178(74.2)$ & $3.5 \pm 0.4$ & $116(77.3)$ & $23.4 \pm 2.4$ & $87(72.5)$ & $14.3 \pm 5.5$ \\
\hline \multicolumn{7}{|l|}{ At codon 680} \\
\hline Asn-Asn & $154(64.2)$ & $3.4 \pm 0.3$ & $94(62.7)$ & $22.3 \pm 1.1$ & $82(68.3)$ & $11.9 \pm 4.5$ \\
\hline Asn/Ser & $49(20.4)$ & $3.3 \pm 0.2$ & $46(30.7)$ & $22.2 \pm 1.2$ & $13(10.8)$ & $14.1 \pm 3.0$ \\
\hline Ser-Ser & $37(15.4)$ & $3.3 \pm 0.4$ & $10(6.6)$ & $23.0 \pm 1.3$ & $25(20.8)$ & $13.4 \pm 3.5$ \\
\hline
\end{tabular}

TABLE 2: Allele combinations considering the FSHR polymorphisms at -29 and codon 680 , genotype distribution, and serum FSH levels (mean $\pm \mathrm{SE}$ ) in men with proven fathers and infertile (nonobstructive azoospermic and severe oligozoospermic). ${ }^{*}$ The first three groups ( 1 , 2 , and 3 ) were combined as one group in the Chi-square test.

\begin{tabular}{|c|c|c|c|c|c|c|c|}
\hline \multirow[t]{2}{*}{ Group } & \multirow{2}{*}{$\begin{array}{l}\text { Allele combination } \\
(-29 / 680)\end{array}$} & \multicolumn{2}{|c|}{$\begin{array}{l}\text { Proven fathers } \\
\quad(n=240)\end{array}$} & \multicolumn{2}{|c|}{$\begin{array}{l}\text { Nonobstructive azoospermic } \\
\qquad(n=150)\end{array}$} & \multicolumn{2}{|c|}{$\begin{array}{c}\text { Severe Oligozoospermic } \\
(n=120)\end{array}$} \\
\hline & & $\begin{array}{l}\text { Frequency } \\
n(\%)\end{array}$ & FSH (IU/I) & $\begin{array}{l}\text { Frequency } \\
n(\%)\end{array}$ & FSH (IU/I) & $\begin{array}{l}\text { Frequency } \\
n(\%)\end{array}$ & FSH (IU/I) \\
\hline $1^{*}$ & A-Asn/A-Asn & $8(3.33)$ & $3.1 \pm 0.4$ & $5(3.33)$ & $23.1 \pm 1.9$ & $4(3.33)$ & $11.3 \pm 5.7$ \\
\hline $2^{*}$ & A-Asn/A-Ser & $2(0.83)$ & $2.9 \pm 0.4$ & $3(2.00)$ & $23.5 \pm 1.9$ & $1(0.83)$ & $12.5 \pm 6.1$ \\
\hline $3^{*}$ & A-Ser/A-Ser & $2(0.83)$ & $3.0 \pm 0.5$ & $1(0.67)$ & $24.0 \pm 2.0$ & $1(0.83)$ & $12.7 \pm 6.4$ \\
\hline 4 & A-Asn/G-Asn & $31(12.92)$ & $3.4 \pm 0.3$ & $17(11.33)$ & $22.4 \pm 1.2$ & $21(17.50)$ & $12.3 \pm 6.8$ \\
\hline 5 & $\begin{array}{l}\text { A-Asn/G-ser or } \\
\text { G-Asn/A-Ser }\end{array}$ & $10(4.17)$ & $3.3 \pm 0.3$ & $8(5.33)$ & $22.8 \pm 1.7$ & $3(2.50)$ & $13.5 \pm 7.2$ \\
\hline 6 & A-Ser/G-Ser & $7(2.92)$ & $3.4 \pm 0.4$ & $2(1.33)$ & $23.3 \pm 1.3$ & $6(5.00)$ & $13.6 \pm 7.4$ \\
\hline 7 & G-Asn/G-Asn & $\begin{array}{l}117 \\
(48.75)\end{array}$ & $3.5 \pm 0.4$ & $73(48.67)$ & $21.5 \pm 1.1$ & $59(49.17)$ & $12.5 \pm 5.5$ \\
\hline 8 & G-Asn/G-Ser & $36(15.00)$ & $3.3 \pm 0.4$ & 34 (22.67) & $21.7 \pm 1.3$ & $8(6.67)$ & $13.7 \pm 6.2$ \\
\hline 9 & G-Ser/G-Ser & $27(11.25)$ & $3.4 \pm 0.4$ & $7(4.67)$ & $22.4 \pm 1.3$ & $17(14.17)$ & $13.8 \pm 6.0$ \\
\hline
\end{tabular}

almost for all investigated groups (except for SNP at nucleotide position -29 for severe oligozoospermic group and SNP 680 FSHR for nonobstructive azoospermic group).

\section{Discussion}

The impact of -29 SNP, alone or in combination with exon 10 SNPs, is less clear but does not seem to influence the clinical parameters or plasma FSH concentrations both in women and men $[8,10,11]$. Our data showed that the genotype distribution of SNP -29 is similar both in proven fathers and infertile men and does not influence serum FSH levels when considered alone. This result was in agreement with those reported in the previous similar studies $[8,10,11]$, but there are differences in the proportions of genotype distribution between our study and others. The possible ethnic differences might be responsible for this difference.

In women with normal ovarian function the polymorphism at codon 680 of the FSHR is an important determinant of ovarian sensitivity to FSH $[6,8,19,25]$. The SNP at codon 680 was firstly confirmed when Aittomaki et al. [26] identified a loss-of-function mutation of FSH receptor in ovarian dysgenesis due to Ala189Val. The SNP at position 680 was then confirmed and has been well studied by Perez Mayorga et al. [6]. The distribution was 29\% for the Asn/Asn, $45 \%$ for the Asn/Ser, and 26\% for the Ser/Ser FSHR variant [6]. In Japan, Sudo et al. [19] reported 522 ovulating women who visited the university hospital. The proportions of genotype Asn-Asn, Asn-Ser, and Ser-Ser were 41.0, 46.9, and $12.1 \%$, respectively. In contrast to observations in women, SNPs in exon 10 of the FSHR have no effect on serum levels of FSH and other clinical parameters in men with either normal or impaired spermatogenesis $[4,7,9]$. Simoni [2] evaluated Asn-Asn, Asn-Ser, and Ser-Ser (37.2, 45.4, and $17.4 \%$, resp.) in populations with proven fertility and (32.0, 48.0, and $20.0 \%$, resp.) infertility, and no significant differences were observed. In another study, Shimoda et al. [15] reported that the proportions of Asn-Asn, Asn-Ser, and Ser-Ser were $38.2,47.3$, and $13.1 \%$, respectively, in subject 
TABLe 3: Allelic frequency in men with proven fathers $(n=240)$ and nonobstructive azoospermic $(n=150)$ and severe oligozoospermic $(n=120)\left(P>.05\right.$ by $\chi^{2}$ test $)$.

\begin{tabular}{|c|c|c|c|c|}
\hline Group & & Proven fathers $n(\%)$ & Nonobstructive azoospermic $n(\%)$ & Severe oligozoospermic $n(\%)$ \\
\hline 1 & A-Asn & $49(10.2)$ & $30(10.0)$ & $30(12.5)$ \\
\hline 2 & A-Ser & $13(2.7)$ & $7(2.3)$ & $9(3.8)$ \\
\hline 3 & G-Asn & $301(62.7)$ & $197(65.7)$ & $147(61.2)$ \\
\hline 4 & G-Ser & $97(20.2)$ & $50(16.7)$ & $48(20.0)$ \\
\hline $5^{*}$ & Undecided & $20(4.2)$ & $16(5.3)$ & $6(2.5)$ \\
\hline
\end{tabular}

* Group 5 consists of alleles 1, 2, 3, and 4, which cannot be distinguished and are included in the statistical analysis as "dummy" variables.

with proven fertility and 49,42 , and $8 \%$ in infertile patients, and there were no significant differences between the two. In our study, the genotype distribution of SNP at codon 680 is different between proven fathers and infertile men but does not influence serum FSH levels when considered alone. This result was in agreement with those reported by Ahda et al. [8]. The differences in the genotype frequency might represent genetic factors contributing to phenotypic expression of severe spermatogenetic impairment. The possible ethnic differences might be responsible for this difference.

When considered in combinations with the SNP in -29 and exon 10 (codon 307 and codon 680), there are a few reports on affected groups with diverse ethnic backgrounds, and the results are not in agreement. A study in German men investigated FSHR SNP genotypes ( -29 , codon 307 and codon 680) alone or in combinations [8]. The authors concluded that while no FSHR haplotype was associated with different serum FSH levels, the A-Ala-Ser and the G-Thr-Asn alleles might represent genetic factors contributing to severe spermatogenetic impairment. A recent meta-analyses of FSHR SNP and male infertility revealed that there is no any association with FSH serum levels or sperm output [13]. A study in Italian men also investigated the same three SNP genotypes and their combinations [11]. The authors concluded that the genotypes had no influence on FSH concentrations in normal or infertile males and did not associate with spermatogenetic impairment. However, very recently a study in Japanese men investigated codon 307 and codon 680 genotypes and concluded that heterozygous combination of Thr/Ala (codon 307) and Ser/Asn (codon 680) was significantly increased in infertile patients compared with the controls but not Ser/Asn alone [15]. In our study, the combination of the SNP at position -29 and codon 680 gives rise to four haplotypes as these alleles show a statistically similar distribution (except the two allelic variants G-Asn/G-Ser G-Ser/G-Ser) in infertile men compared to proven fathers and suggests that these alleles might not represent a risk factor for male infertility.

In the test for deviation from Hardy-Weinberg proportions, the deviation from the Hardy-Weinberg equilibrium (excess of homozygosity) takes place almost for all investigated groups (except for SNP at nucleotide position -29 for severe oligozoospermic group and SNP 680 FSHR for nonobstructive azoospermic group). This deviation is very important with regard to high parental consanguinity in populations like Turkey.
In conclusion, our data demonstrate that FSHR gene polymorphisms seem not to have a direct influence on spermatogenesis, but are differently distributed, identifying an additional genetic factor possibly contributing to the multigenic origin of male infertility. The discrepancies are most likely due either to study subjects by chance or to study different genetic backgrounds in different populations. In populations like Turkey, high parental consanguinity could bring out genetic factors or provide permissive background for complex disorders. Additional studies on well-defined populations of infertile men will probably clarify these aspects.

\section{Acknowledgments}

The authors collectively thank Dr. Selahaddin Tekes for his individual help in organizing and planning, and for the assistance with data management, analysis, and interpretation. Part of this study was presented as poster presentation at the III. International Congress of Molecular Medicine, 5-8 May 2009, Istanbul, Turkey.

\section{References}

[1] M. Simoni, J. Gromoll, and E. Nieschlag, "The folliclestimulating hormone receptor: biochemistry, molecular biology, physiology, and pathophysiology," Endocrine Reviews, vol. 18 , no. 6, pp. 739-773, 1997.

[2] M. Simoni, "Mutations of the G protein-coupled receptors of the hypothalamo-pituitary-gonadal axis. Where do we stand?" European Journal of Endocrinology, vol. 139, no. 2, pp. 145147, 1998.

[3] M. Simoni, J. Gromoll, W. Höppner, et al., "Mutational analysis of the follicle-stimulating hormone (FSH) receptor in normal and infertile men: identification and characterization of two discrete FSH receptor isoforms," Journal of Clinical Endocrinology and Metabolism, vol. 84, no. 2, pp. 751-755, 1999.

[4] M. Simoni, E. Nieschlag, and J. Gromoll, "Isoforms and single nucleotide polymorphism of the FSH receptor gene: implications for human reproduction," Human Reproduction Update, vol. 8, no. 5, pp. 413-421, 2002.

[5] J. Gromoll, M. Bröcker, M. Derwahl, and W. Höppner, "Detection of mutations in glycoprotein hormone receptors," Methods, vol. 21, no. 1, pp. 83-97, 2000.

[6] M. Perez Mayorga, J. Gromoll, H. M. Behre, C. Gassner, E. Nieschlag, and M. Simoni, "Ovarian response to folliclestimulating hormone (FSH) stimulation depends on the FSH 
receptor genotype," Journal of Clinical Endocrinology and Metabolism, vol. 85, no. 9, pp. 3365-3369, 2000.

[7] K. Asatiani, J. Gromoll, S. V. Eckardstein, M. Zitzmann, E. Nieschlag, and M. Simoni, "Distribution and function of FSH receptor genetic variants in normal men," Andrologia, vol. 34, no. 3, pp. 172-176, 2002.

[8] Y. Ahda, J. Gromoll, A. Wunsch, et al., "Follicle-stimulating hormone receptor gene haplotype distribution in normozoospermic and azoospermic men," Journal of Andrology, vol. 26, no. 4, pp. 494-499, 2005.

[9] J. Gromoll and M. Simoni, "Genetic complexity of FSH receptor function," Trends in Endocrinology and Metabolism, vol. 16, no. 8, pp. 368-373, 2005.

[10] A. Wunsch, Y. Ahda, F. Banaz-Yaşar, et al., "Single-nucleotide polymorphisms in the promoter region influence the expression of the human follicle-stimulating hormone receptor," Fertility and Sterility, vol. 84, no. 2, pp. 446-453, 2005.

[11] M. Pengo, A. Ferlin, B. Arredi, et al., "FSH receptor gene polymorphisms in fertile and infertile Italian men," Reproductive BioMedicine Online, vol. 13, no. 6, pp. 795-800, 2006.

[12] C. Krausz and C. Giachini, "Genetic risk factors in male infertility," Archives of Andrology, vol. 53, no. 3, pp. 125-133, 2007.

[13] F. Tüttelmann, E. Rajpert-De Meyts, E. Nieschlag, and M. Simoni, "Gene polymorphisms and male infertility-a meta-analysis and literature review," Reproductive BioMedicine Online, vol. 15, no. 6, pp. 643-658, 2007.

[14] A. A. Zalata, A. H. Hassan, H. A. Nada, F. M. Bragais, A. Agarwal, and T. Mostafa, "Follicle-stimulating hormone receptor polymorphism and seminal anti-Müllerian hormone in fertile and infertile men," Andrologia, vol. 40, no. 6, pp. 392 $397,2008$.

[15] C. Shimoda, E. Koh, K. Yamamoto, et al., "Single nucleotide polymorphism analysis of the follicle-stimulating hormone (FSH) receptor in Japanese with male infertility: identification of codon combination with heterozygous variations of the two discrete FSH receptor gene," Endocrine Journal, vol. 56, no. 7, pp. 859-865, 2009.

[16] L. T. Putowski, W. J. Schillings, C. M. Lee, E. P. Reddy, and J. A. Jakowicki, "Human follicle-stimulating hormone receptor (FSH-R) promoter/enhancer activity is inhibited by transcriptional factors, from the upstream stimulating factors family, via E-box and newly identified initiator element (Inr) in FSHR non-expressing cells," Gynecological Endocrinology, vol. 19, no. 1, pp. 9-17, 2004.

[17] J. Y. Liu, J. Gromoll, M. I. Cedars, and A. R. La Barbera, "Identification of allelic variants in the follicle-stimulating hormone receptor genes of females with or without hypergonadotropic amenorrhea," Fertility and Sterility, vol. 70, no. 2, pp. 326-331, 1998.

[18] G. S. Conway, E. Conway, C. Walker, W. Höppner, J. Gromoll, and M. Simoni, "Mutation screening and isoform prevalence of the follicle stimulating hormone receptor gene in women with premature ovarian failure, resistant ovary syndrome and polycystic ovary syndrome," Clinical Endocrinology, vol. 51, no. 1, pp. 97-99, 1999.

[19] S. Sudo, M. Kudo, S. Wada, O. Sato, A. J. W. Hsueh, and S. Fujimoto, "Genetic and functional analyses of polymorphisms in the human FSH receptor gene," Molecular Human Reproduction, vol. 8, no. 10, pp. 893-899, 2002.

[20] J. S. E. Laven, A. G. M. G. J. Mulders, D. A. Suryandari, et al., "Follicle-stimulating hormone receptor polymorphisms in women with normogonadotropic anovulatory infertility," Fertility and Sterility, vol. 80, no. 4, pp. 986-992, 2003.
[21] M. Poncz, D. Solowiejczyk, B. Harpel, Y. Mory, E. Schwartz, and S. Surrey, "Construction of human gene libraries from small amounts of peripheral blood: analysis of $\beta$-like globin genes," Hemoglobin, vol. 6, no. 1, pp. 27-36, 1982.

[22] S. A. Miller, D. D. Dykes, and H. F. Polesky, "A simple salting out procedure for extracting DNA from human nucleated cells," Nucleic Acids Research, vol. 16, no. 3, p. 1215, 1988.

[23] C. Q. Yang, K. Y. K. Chan, H. Y. S. Ngan, et al., "Single nucleotide polymorphisms of follicle-stimulating hormone receptor are associated with ovarian cancer susceptibility," Carcinogenesis, vol. 27, no. 7, pp. 1502-1506, 2006.

[24] World Health Organization. WHO, Laboratory Manual for the Examination of Human Semen and Semen-Cervical Mucus Interactions, Cambridge University Press, Cambridge, UK, 4th edition, 1999.

[25] F. de Castro, F. J. Morón, L. Montoro, et al., "Human controlled ovarian hyperstimulation outcome is a polygenic trait," Pharmacogenetics, vol. 14, no. 5, pp. 285-293, 2004.

[26] K. Aittomaki, J. L. Lucena, P. Pakarinen, et al., "Mutation in the follicle-stimulating hormone receptor gene causes hereditary hypergonadotropic ovarian failure," Cell, vol. 82, no. 6, pp. 959-968, 1995. 


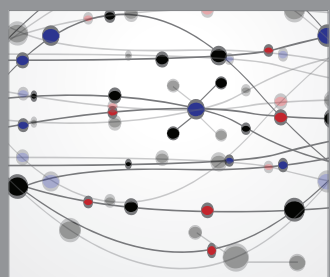

The Scientific World Journal
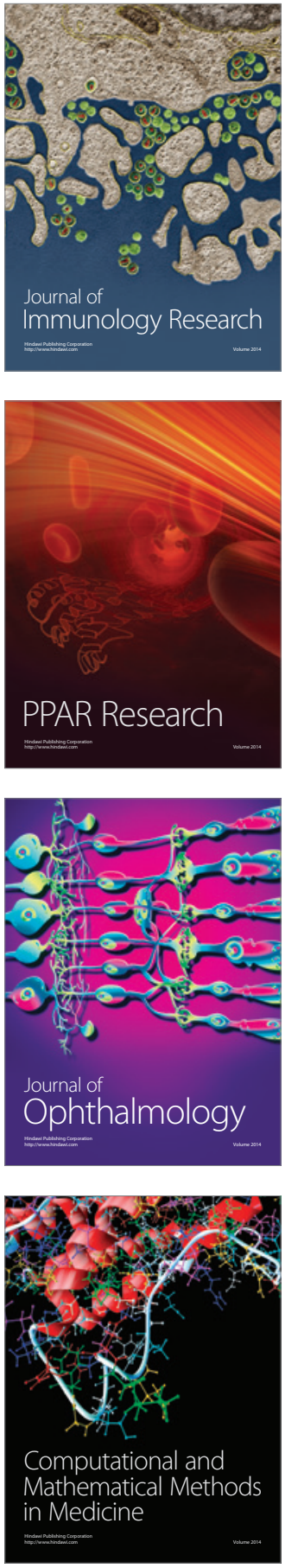

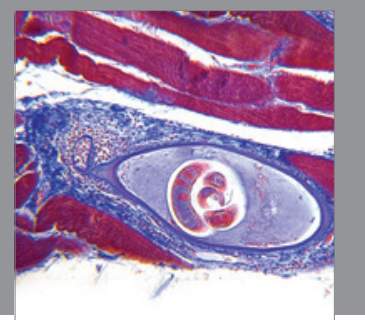

Gastroenterology

Research and Practice
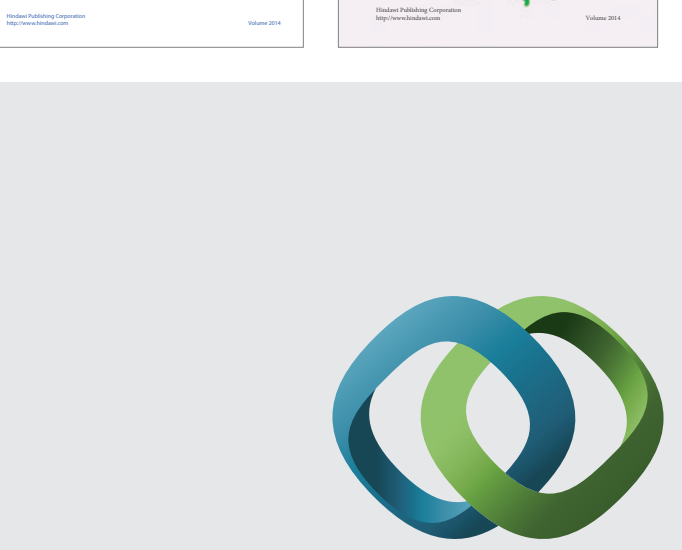

\section{Hindawi}

Submit your manuscripts at

http://www.hindawi.com
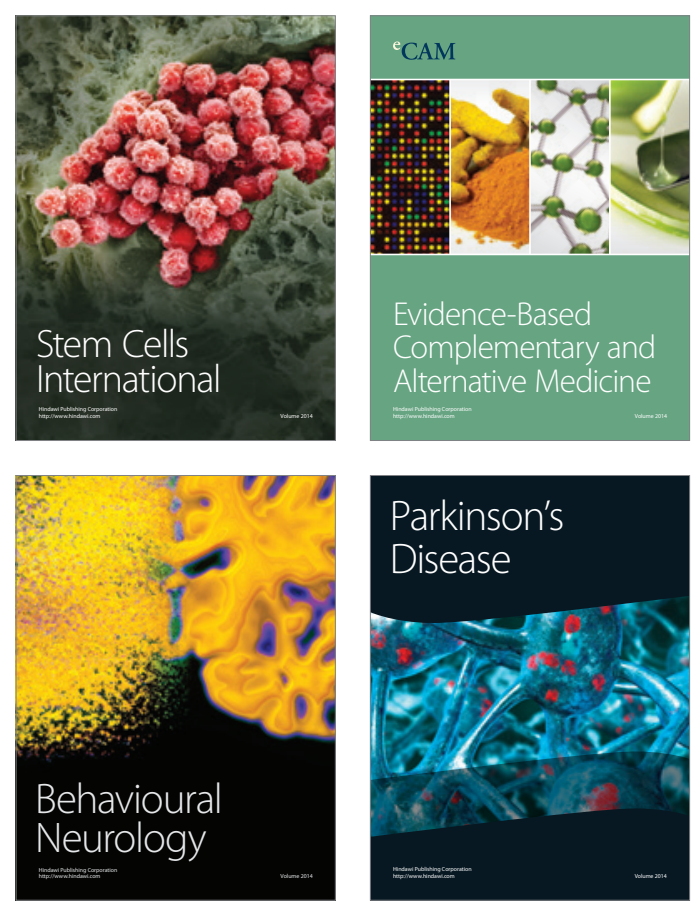

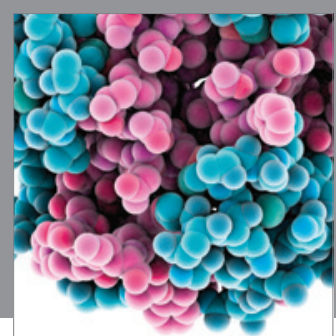

Journal of
Diabetes Research

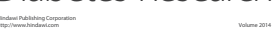

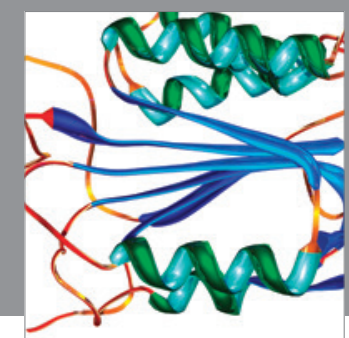

Disease Markers
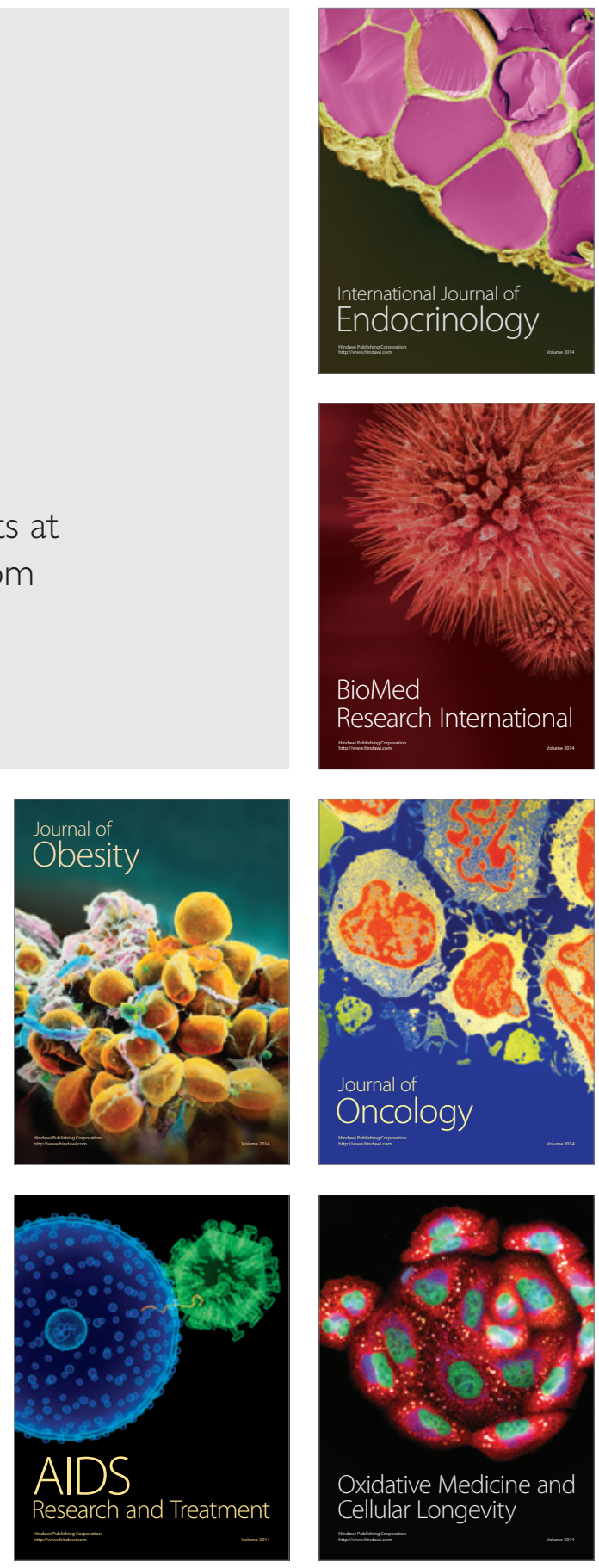